\title{
Comportamiento de las firmas de contadores públicos en el municipio Maracaibo*
}

\author{
Gómez de Angulo, Oda H.** \\ Chirinos González, Alira*** \\ Herrera, Diego ${ }^{\star \star * *}$
}

\section{Resumen}

El presente artículo tiene como objetivo analizar el comportamiento de las firmas de contadores públicos del municipio Maracaibo, estado Zulia-Venezuela, con el propósito de dar aportes para mejorar la formación académica del contador público. El estudio es de tipo descriptivo, de campo, no experimental, se aplicó una encuesta a veinticuatro (24) firmas que visan sus estados financieros en el Colegio de Contadores Públicos del Estado Zulia, seleccionadas aleatoriamente. Los resultados obtenidos muestran un estancamiento en el crecimiento de las firmas de contadores públicos de la región y diversificación de los servicios ofrecidos como respuesta a las actuales exigencias del mercado. Se concluye que la contaduría se encuentra en un proceso de transformación, donde se exige mayor responsabilidad en la ejecución del trabajo, siendo necesario adaptar los programas académicos a las nuevas necesidades del ámbito laboral.

Palabras clave: Firma de contadores públicos, formación académica, modelos organizativos, servicios de contaduría, municipio Maracaibo.

\section{Recibido: 04-06-05. Aceptado: 05-03-17}

* Este artículo corresponde al Proyecto de Investigación "Desarrollo de las Firmas de Contadores Públicos en el municipio Maracaibo", adscrito al Centro de Estudios de la Empresa (CEE) de la Universidad del Zulia (LUZ) y financiado por el Consejo de Desarrollo Científico y Humanístico de LUZ.

** Mgs. en Gerencia Financiera. Profa de la Fac de Cs Econ y Soc de LUZ. Adscrita al CEE. E-mail: Odagomez@cantv.net.ve

*** Lic. en Contaduría Pública. Becaria Académica del CEE de LUZ. E-mail: alirachirinos@intercable.net.ve

**** Lic. en Contaduría Pública. Auxiliar de Investigación del CEE de LUZ. E-mail: dherrera@polinter.com.ve 


\section{The Behaviour of Public Accounting Firms in Maracaibo. Municipality}

\section{Abstract}

The objective of this article is to analyze the bahaviour of public accounting firms in Maracaibo Municipio, Zulia State, Venezuela, for the purpose of supporting the advancement of academic preparation for these professionals. The study is descriptive, field based, and non-experimental, and a survey questionaire was applied to twenty-four (24) accounting firms selected at random, that register their financial statements in the Public Accountants Association in Zulia State. The results obtained indicate stagnation in public accounting firm growth in the region and the diversification of services offered as a reaction to present market demands. The conclusion is that accounting as a practice is immersed in a process of transformation where more responsibility is required in the execution of their services, and where it is necessary to adapt academic programs to the needs of the labor field.

Key words: Public accounting firms, academic formation, organizational models, accounting services, Maracaibo Municipality.

\section{Introducción}

El Centro de Estudios de la Empresa en los últimos años ha logrado impulsar la investigación en las empresas privadas, sin embargo, tenía pendiente el desarrollo de investigaciones directamente vinculadas a la disciplina contable, ya que dentro de la Facultad de Ciencias Económicas y Sociales de la Universidad del Zulia, se encuentra la Escuela de Administración y Contaduría, de la cual egresan los licenciados en contaduría pública, quienes se pueden asociar y constituirse en firmas de contadores públicos, para prestar sus servicios profesionales.

Con el propósito de mejorar los procesos de formación académica de la contaduría pública, se aprobó el proyecto de investigación "Desarrollo de firmas de contadores públicos en el municipio Maracaibo", dentro del programa de investigación titulado "DESARROLLO DE LA CONTADURÍA PÚBLICA EN VENEZUELA".
La Contaduría Pública es considerada como una profesión que desempeña un papel muy importante en todas las sociedades. A medida que el mundo de los negocios se mueve hacia economías de mercados, y con las inversiones y operaciones que traspasan las fronteras geográficas en mayor extensión, el contador público debe tener una perspectiva global más amplia para entender el contexto en el cual operan los negocios.

De acuerdo a lo establecido en la Ley del Ejercicio de la Contaduría Pública y su Reglamento, cualquier contador público que se asocie con otro u otros contadores públicos podrá establecer o constituir una firma u organización profesional. Con el propósito de analizar el comportamiento de las firmas de contadores públicos en el municipio Maracaibo, la investigación se planteó los siguientes objetivos específicos: 1. Analizar el crecimiento de firmas de contadores públicos en el municipio Maracaibo; 2. Identificar el grado de diversificación de los servicios prestados 
por las firmas de contadores públicos; 3. Describir los servicios prestados por las diferentes firmas de contadores públicos; 4. Caracterizar al personal de las firmas, en cuanto a su formación, experiencia, rotación, promoción, entre otros; 5. Identificar el modelo organizativo de la firma.

Para que este proyecto de investigación lograra los objetivos antes planteados se efectuó una revisión bibliográfica y exploración empírica, donde se pudo evidenciar que el Colegio de Contadores Públicos del Estado Zulia no lleva un registro de las firmas que funcionan actualmente en la región; sólo se pudo localizar un trabajo de investigación de Torres (2002), que trata sobre este particular, titulado "Estrategias financieras para maximizar los beneficios en las pequeñas y medianas firmas de contadores públicos del municipio Maracaibo", a través del cual se obtuvo información de un listado de cincuenta y cinco firmas que visan los estados financieros de sus clientes.

Con el fin de cumplir con los objetivos antes planteados, se realizaron entrevistas estructuradas, mediante la aplicación de encuestas a veinticuatro firmas de contadores públicos del municipio Maracaibo que visan los estados financieros de sus clientes en el Colegio de Contadores Públicos del Estado Zulia, las cuales fueron seleccionadas de forma aleatoria; una vez iniciado dicho proceso fueron sustituidas algunas seleccionadas en la muestra inicial por otras, ya que unas se fusionaron y otras que eran representantes de firmas transnacionales presentaron muchas limitaciones para entregar la información, por lo que se decidió su exclusión.

\section{Las firmas de contadores públicos}

Las firmas de contadores públicos son sociedades civiles, que se rigen por las disposiciones legales venezolanas, la Ley del Ejercicio de la Contaduría y su Reglamento, el Código de Ética Profesional del Colegio Profesional del Contador Público Venezolano y por las normas y estipulaciones establecidas en el documento de constitución de las mismas, cuyo propósito es prestar servicios que se encuentren enmarcados dentro del ejercicio de la profesión.

Actualmente el Colegio de Contadores Públicos del Estado Zulia, no lleva un registro o control sobre las firmas que ejercen la contaduría pública bajo esta jurisdicción, ya que el cumplimiento de las disposiciones y normativas establecidas para el ejercicio de esta profesión, es responsabilidad de los profesionales de la contaduría pública, quiénes deben estar inscritos y solventes para poder visar los estados financieros.

De acuerdo al artículo 12 de la Ley del Ejercicio de la Contaduría Pública: "cualquier contador público podrá establecer una firma u organización profesional, asociándose con otro $u$ otros contadores públicos, la cual podrá dedicarse al ejercicio de actividades propias de esta profesión, de conformidad con esta ley. La asociación así constituida, deberá contener los nombres de los socios y tendrá carácter civil, pero en todo caso la responsabilidad por sus actuaciones siempre estará a cargo de los asociados, quienes necesariamente deberán estar inscritos en el Colegio Profesional de la 
Entidad Federal donde esté domiciliada la firma o empresa".

Por lo tanto, las firmas de contadores públicos no se pueden constituir en sociedades mercantiles, en caso de que así lo hicieren no podrán realizar las actividades indicadas como ejercicio profesional en la Ley del Ejercicio y su Reglamento.

La Federación de Colegios de Contadores Públicos, consciente de la responsabilidad del contador público ante la sociedad y tomando en cuenta las exigencias de credibilidad y confianza de los servicios profesionales que presta a sus agremiados, emitió en el año 1996 el Código de Ética Profesional del Contador Público Venezolano, donde se establecen las disposiciones éticas que debe observar el contador público en relación a los clientes, a los colegas y al gremio. Así como también, está trabajando en las normas de calidad, que ayuden a fortalecer la confianza del público en general de esta profesión, dentro de las cuales se encuentra la Declaración sobre Normas y Procedimientos de Auditoria №12 (DNA12), referente al control de calidad en el ejercicio profesional.

La DNA-12 constituye una guía para las firmas de contadores públicos y profesionales independientes que presten sus servicios en forma individual, en relación con las políticas y procedimientos sobre el control de calidad. En esta declaración se establece que las firmas de contadores públicos deberán implementar políticas y procedimientos de control de calidad debidamente enfocados para asegurar que todos los trabajos son ejecutados de acuerdo con las normas y procedimientos de auditoria. Esta decla- ración no difiere mucho de lo planteado en el Boletín 3020 emitido por el Instituto Mexicano de Contadores Públicos (IMCP, 2004) en cuanto a los aspectos que deben ser considerados para definir los objetivos de las políticas y procedimientos de control de calidad, estos son: requisitos profesionales, habilidades y competencia, asignación del personal, delegación, consultas, aceptación y retención de clientes, monitoreo de la eficiencia del control de calidad y otras que sean aplicables específicamente al área de auditoria y en las etapas de dirección, supervisión y revisión.

Actualmente las firmas están siendo afectadas por la situación política y económica del país, por la globalización, por un proceso de cambio y competitividad; que obliga a elevar sus índices de productividad, lograr mayor eficiencia y brindar un servicio de calidad.

Por lo tanto, Morrow (2000:9) señala que el éxito futuro de la profesión contable depende en gran medida de:

- "La percepción pública de las habilidades y actuaciones del contador público.

- Los contadores públicos deben guiarse por las fuerzas del mercado y no ser dependientes de las regulaciones que los mantengan en el negocio.

- El mercado demanda menos auditoria y contabilidad y más servicios de asesoría con valor agregado.

- La especialización es crítica para el futuro de la profesión contable.

- El mercado demanda que los contadores públicos sean conocedores de las prácticas y estrategias de los negocios globales". 


\section{Crecimiento de las firmas de contadores públicos en el municipio Maracaibo}

Uno de los objetivos de esta investigación es conocer el crecimiento de las firmas, por lo que se incluyó una pregunta en la encuesta para conocer el año de inicio de actividades de cada una de ellas, obteniendo los siguientes resultados:

Como se observa en el Gráfico 1, las firmas de contadores públicos, se han incrementado en forma progresiva desde el año 1992, manteniéndose estable su crecimiento durante los años 1993 y 1994, siguiendo su incremento a partir del año 1995 hasta el año 1999. En los últimos cuatro años no se presenta creación de nuevas firmas, según información suministrada por los entrevistados, tal situación, se debe principalmente a la recesiòn económica que ha experimentado nuestro país en los últimos años, limitando el crecimiento de sus clientes, lo cual ha afectado directamente el crecimiento de sus organizaciones.

Tomando en consideración que las firmas de contadores públicos, constitu- yen una de las fuentes de trabajo para los nuevos profesionales de la contaduría pública y con el propósito de hacer un vínculo con lo que está sucediendo en la Universidad del Zulia, se presenta la siguiente información:

Como se puede observar en la Tabla 1, desde el año 1997 hasta el 2001 inclusive, el número de egresados de contadores públicos de la Universidad del Zulia se ha incrementado en mayor proporción que el crecimiento que se observa en las firmas para esos mismos años, en el Gráfico 1, sin tomar en cuenta los egresados de las otras universidades locales, como son: Universidad Dr. José Gregorio Hernández, Universidad Nacional Abierta (UNA), Universidad Rafael Urdaneta (URU) y Universidad Rafael Belloso Chacín (URBE); la situación es preocupante, ya que no se observa crecimiento en una de las fuentes de trabajo de los nuevos profesionales.

Es importante mencionar, que la situación antes planteada es muy diferente a lo que está sucediendo a nivel de los Estados Unidos y Puerto Rico, ya que según Huertas (2002) el número de estu-

\section{Gráfico 1}
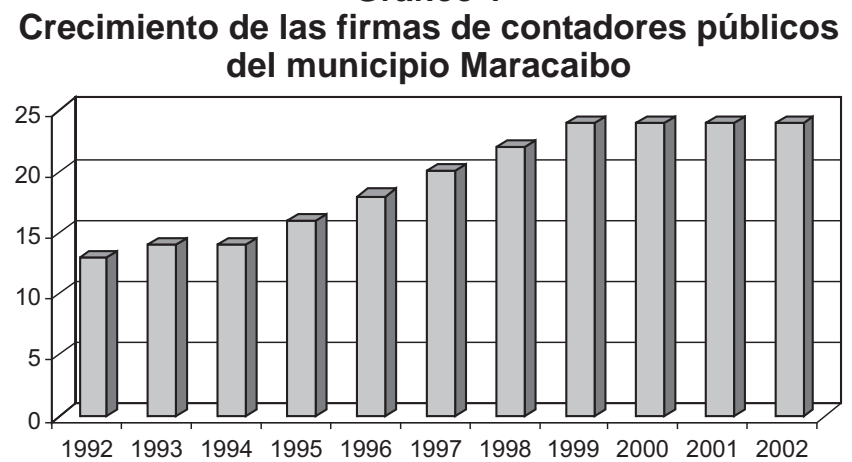

Fuente: Elaboración propia sobre la base de los resultados obtenidos en las encuestas. 


\section{Tabla 1}

Número de Estudiantes de Contaduría Pública

Escuela de Administración y Contaduría de la Universidad del Zulia

\begin{tabular}{lccccc}
\hline & $\mathbf{1 9 9 7}$ & $\mathbf{1 9 9 8}$ & $\mathbf{1 9 9 9}$ & $\mathbf{2 0 0 0}$ & $\mathbf{2 0 0 1}$ \\
\hline CNU & 204 & 221 & 249 & 385 & 399 \\
Institutos Tecnológicos y otros & 507 & 196 & 218 & 64 & 483 \\
Equivalencias & 2 & 1 & 37 & 73 & 57 \\
Cambios y reincorporaciones & 123 & 57 & 203 & 240 & 169 \\
Total ingresos & $\mathbf{8 3 6}$ & $\mathbf{4 7 5}$ & $\mathbf{7 0 7}$ & $\mathbf{7 6 2}$ & $\mathbf{1 . 1 0 8}$ \\
Total egresos & $\mathbf{1 2 5}$ & $\mathbf{1 9 3}$ & $\mathbf{2 2 4}$ & $\mathbf{2 7 8}$ & $\mathbf{2 8 2}$ \\
\hline
\end{tabular}

Fuente: Adaptado de Navarro (2003).

diantes que se interesa por ingresar en la profesión de contaduría pública en los Estados Unidos y en Puerto Rico ha disminuido en aproximadamente un $23 \%$. El hecho de que el número de estudiantes que aspira a estudiar contabilidad ha disminuido de forma significativa es un indicador de que quizás la población estudiantil visualiza que un graduado universitario con título de contador público, no es tan competitivo en estos tiempos como uno con especialidad en mercadeo, finanzas o sistemas de información. Adicionalmente los recientes acontecimientos a nivel mundial asociados a fraudes financieros han originado el establecimiento de normativas y regulaciones abocadas a mitigar este tipo de situaciones, así como a regular las actuaciones profesionales del contador público, lo cual hace cada día más riesgosa y exigente esta profesión.

Pareciera que lo antes planteado no afecta a nuestro país porque son ámbitos geográficos y económicos muy diferentes, sin embargo, no se debe olvidar que nos encontramos en un proceso de globalización, de tal manera que lo que ha sucedido en otras localidades puede afectar al ejercicio profesional de la contaduría a nivel nacional. Todos los profesionales en el área contable, tienen conocimiento público de los fraudes ocurridos a nivel internacional en las empresas, y que a raíz de esta situación los organismos reguladores de la presentación de la información financiera, han emitido nuevas disposiciones y regulaciones, que afectan la responsabilidad del contador público en cualquier ámbito geográfico del mundo.

En este orden de ideas, también se debe tener presente que los Principios Contables y las Normas de Auditoria Interna y Externa que se aplican en Venezuela, son copias o adaptaciones de otros países y que actualmente nuestra profesión se encuentra en un proceso de adopción de las normas internacionales de contabilidad y auditoria. Adicionalmente, en nuestro país existe un estado de incertidumbre política y económica, la recesión global en que las empresas están implantando recortes presupuestarios a sus proyectos de capital y nóminas. Son indicadores que llaman a la reflexión, que exigen investigar, si están los conta- 
dores preparados para enfrentar los retos del cambio y la incertidumbre del país, cuáles son las competencias que capacitan a los contadores para ser exitosos y cuál es el rol de los educadores, las organizaciones profesionales y las empresas, para poder determinar si se justifica de acuerdo a las demandas del mercado local y nacional el crecimiento de los estudiantes de contaduría pública o si por el contrario se debe estar estudiando la posibilidad de ofrecer otras carreras de acuerdo a las necesidades y demandas del mercado.

Por otra parte, con el fin de conocer el crecimiento interno de las firmas, se les preguntó el número de clientes que han tenido en los últimos tres años, obteniendo los resultados mostrados en la Tabla 2, donde se observa que el comportamiento de los clientes no es uniforme, por lo que tenemos que 11 de ellas presentan decrecimiento en su cartera de clientes, mientras que 13 presentan crecimiento. En términos generales, al comparar los resultados de las 24 firmas encuestadas, se aprecia que el incremento de su número de clientes está en un 3\% para el año 2001 y en $1 \%$ para el año 2002. Sin embargo, los resultados por segmentos indican que el $46 \%$ de las de ellas presentan para ambos años un decrecimiento de más de un $10 \%$ en su cartera de clientes, mientras que el $54 \%$ presenta para ambos años un crecimiento de más del $10 \%$ en sus clientes; tal situación indica que el crecimiento interno de algunas firmas ha sido producto de la disminución de clientes de otras, debido a la competencia que existe para mantenerse en el mercado, donde algunas se han visto en la necesidad de reducir los costos de sus servicios profesionales y otras han utilizado sus competencias para satisfacer las necesidades de sus clientes, a través de la innovación continua, aprovechando al máximo los recursos, conocimientos y atributos de los que dispone para dar el mejor servicio de acuerdo a las necesidades del cliente que permitan mejorar el desempeño de su negocio.

\section{Servicios prestados por las firmas de contadores públicos}

Sobre la base de la revisión bibliográfica y el trabajo de campo se logró constatar que las firmas, prestan varios servicios, los cuales se rigen por la Ley del Ejercicio de la Contaduría Pública, el reglamento respectivo, el Código de Ética y los principios y normas que guían el

Tabla 2

Número de clientes de las firmas

\begin{tabular}{cccc}
\hline \multirow{2}{*}{$\begin{array}{c}\text { No Firmas } \\
\text { Encuestadas }\end{array}$} & Año 2000 & Año 2001 & Año 2002 \\
\cline { 2 - 4 } & 498 & 419 & 324 \\
$11 \mathrm{a}$ & 888 & 1.002 & 1.111 \\
$13 \mathrm{~b}$ & 1.386 & 1.421 & 1.435 \\
\hline 24 & \multicolumn{3}{c}{ ' Firmas de crecimiento }
\end{tabular}

Fuente: Elaboración propia sobre la base de los resultados obtenidos en las encuestas. 
ejercicio profesional. Para efectos de esta investigación, los servicios fueron agrupados en las áreas de: contabilidad, auditoria externa e interna, auditoria operacional, asesoría fiscal, auditoria de sistemas de información, figurar como comisario, consultoría gerencial y outsorcing, logrando realizar una breve descripción para cada uno de ellos, como se presenta a continuación:

\subsection{Contabilidad}

El servicio de Contabilidad es considerado uno de los campos de mayor actuación de las pequeñas firmas, ya que existen gran cantidad de empresas de mediana capacidad administrativa, que no tienen suficientes recursos económicos, para mantener en su nómina personal en el área contable, por lo que recurren a las firmas para que se encarguen del aspecto contable del negocio.

El objetivo fundamental del servicio de contabilidad es producir información financiera, que permitan analizar la situación económica y financiera de la entidad, para la toma de decisiones, de acuerdo a la naturaleza y tamaño de la empresa. Dentro de las actividades más resaltantes de este servicio se encuentran: formular el código de cuentas, procesamiento de la contabilidad mediante los programas de computación, emisión de reportes mensuales computarizados, formulación de los estados financieros y demás información contable, interpretación y análisis de estados financieros, actualización de los libros legales, servicios especiales de contabilidad (conciliaciones bancarias, depuración y análisis de cuentas, entre otros), asesoría en materia de reexpresión de estados financieros por efectos de la inflación (DPC-10), certificación de ingresos, elaboración de flujos de cajas proyectados.

\subsection{Auditoria externa}

La actividad principal del servicio de Auditoria consiste en el examen de los estados financieros de las empresas. Este servicio se efectúa con la finalidad de emitir una opinión profesional, objetiva, imparcial e independiente sobre la razonabilidad de los estados financieros, que son manifestaciones de la gerencia de la empresa. Para poder determinar la razonabilidad de los estados financieros, se toman en cuenta los registros contables, las transacciones financieras que originan tales datos y la apropiada aplicación de los principios de contabilidad y las normas de auditoria de aceptación general en Venezuela y de acuerdo a las normativas contables que rigen las operaciones de empresas en sectores especializados (Bancos, empresas de seguros, entre otros).

Por otra parte, se pueden realizar auditorias distintas a la de estados financieros, las cuales se refieren al cumplimiento de acuerdos, convenios o requisitos reglamentarios relacionados con la información financiera.

Dentro de las actividades más resaltantes en el servicio de auditoria externa, se encuentran: revisión de los estados financieros, revisiones especiales, evaluación de cumplimiento de convenios o requisitos reglamentarios, examen del control interno contable y administrativo, planificación y ejecución de tomas físicas de inventarios y/o propiedad, planta y equipo $y$, cualquier otro servicio, en aras 
de determinar la razonabilidad de los estados financieros.

\subsection{Auditoria Interna}

De acuerdo a León (2003), el Instituto de Auditores Internos de los Estados Unidos define la auditoria interna como una actividad independiente que tiene lugar dentro de la empresa y que está encaminada a la revisión de operaciones contables y de otra naturaleza, con la finalidad de prestar un servicio a la dirección.

Este servicio, nace como una necesidad que tienen las empresas de tener una evaluación independiente de sus actividades por personal de la empresa. Sin embargo, dado los costos que implica para muchas empresas mantener este personal dentro de su organización, se han visto en la necesidad de requerir este servicio a las firmas de contadores públicos.

Este servicio se realiza para ayudar a los miembros de una organización en el cumplimiento efectivo de sus responsabilidades, proporcionando: análisis, evaluaciones, asesorías y recomendaciones, que promuevan la eficiencia financiera y operacional de la empresa. Dentro de las actividades más resaltantes se tiene: evaluación del área financiera, del área de costos y del área operativa, auditoria de sistemas de información o gestión de riesgos informáticos.

\subsection{Auditoria Operacional}

Auditoria operacional es el examen posterior, profesional, objetivo y sistemático de la totalidad o parte de las operaciones o actividades de una entidad, proyec- to, programa, inversión o contrato en particular, sus unidades integrantes u operaciones específicas, con el fin de medir su desempeño.

El método general para realizar una auditoria operacional es similar al utilizado en auditoria financiera. Está dado por normas, técnicas y procedimientos que se desarrollan mediante programas de trabajo.

Su propósito es determinar los grados de efectividad, economía y eficiencia alcanzados por el ente auditado, y formular recomendaciones para mejorar las operaciones evaluadas.

\subsection{Asesoría fiscal}

La Asesoría Fiscal tiene como fin brindar a los clientes el aprovechamiento de las bondades tributarias al máximo, sin exponer a las organizaciones a contingencias por el incumplimiento de las obligaciones fiscales. Dentro de los servicios más resaltantes se encuentran: revisión o preparación de las declaraciones de rentas: impuesto sobre la renta (I.S.L.R), a los Activos Empresariales (I.A.E.), Impuestos Municipales, entre otros deberes formales; revisión y control de las retenciones del Impuesto sobre la Renta (Decreto 1808) y preparación de la relación anual (RA); revisión del cumplimiento de las obligaciones de los agentes de retención y contribuyentes al impuesto del valor agregado (IVA); asistencia en procesos de fiscalización y revisión de la situación fiscal para los años no prescritos; asesoramiento en el cumplimiento de las disposiciones establecidas en las diferentes leyes de orden tributario. 


\subsection{Auditoria de Sistemas de información}

"La auditoria de los sistemas de información se define como cualquier auditoria que abarca la revisión y evaluación de todos los aspectos (o de cualquier porción de ellos) de los sistemas automáticos de procesamiento de la información, incluidos los procedimientos no automáticos relacionados con ellos y las interfases correspondientes" (Asociación de Auditoria y Control en Sistemas de Información, 2002).

En los procesos administrativos de la empresa, los sistemas de computación deben mejorar la eficiencia y el control sobre las operaciones de la empresa, por eso las firmas ofrecen los servicios de: asistencia en la escogencia de software adecuado a sus necesidades, evaluación de los controles de los sistemas de información, evaluación de la eficiencia del centro de informática o procesamiento de la información contable, revisión de la seguridad de los datos y desarrollo de planes de contingencias para sistemas de información.

\subsection{Figurar como comisario}

"En Venezuela, las atribuciones del comisario tienen un carácter amplio. EI servicio de comisario representa una institución legal que tiene facultades de vigilancia integral en función del cumplimiento, de parte de los administradores de sociedades mercantiles, de aspectos legales, administrativos, económicos, financieros y estatutarios" (Rosales, 1999:68).

El comisario como integrante del órgano de vigilancia de una sociedad anónima, tiene la función principal de vigilar las operaciones de los administradores de la sociedad, de informar a los accionistas respecto a las irregularidades que observe.

En tal sentido, debe entregar un informe a la asamblea ordinaria de accionistas o socios, indicando el alcance del trabajo realizado y el resultado de la evaluación de la gestión administrativa de las operaciones económico-financieras de la empresa, con el objeto de sugerir la aprobación, o no, de la gestión administrativa de la entidad.

\subsection{Consultoría gerencial}

Esta actividad profesional está ejerciendo una influencia cada vez mayor en la toma de decisiones a nivel gerencial en los negocios. Dada la creciente complejidad de la Gerencia moderna, y la disponibilidad de técnicas científicas actuales, hasta los ejecutivos más experimentados acuden a consultores externos para recabar de estos asesoramientos especializados que les permita enfrentar las exigencias que el actual mundo de los negocios impone.

Es por ello que sus servicios en el área de asesoría gerencial, incluyen: estudios organizacionales, planificación financiera, desarrollo de sistemas de información computarizados, optimización de servicios administrativos y contables, a través de la elaboración de manuales sobre organización, métodos y procedimientos administrativos; todos orientados a proporcionar un servicio de calidad y eficiencia a fin de desarrollar una organización exitosa. 


\subsection{Outsuorcing}

La palabra outsourcing, hace referencia a la fuente externa de suministro de servicios; es decir, la subcontratación de operaciones de una compañía a contratistas externas. Con frecuencia se recurre al outsourcing como mecanismo para reducir costos, lo cual en algunos casos alcanza hasta un $40 \%$. Dicha subcontratación ofrece servicios modernos y especializados, sin que la empresa tenga que descapitalizarse por invertir en infraestructura (García, 2002).

Producto de la globalización, la creciente complejidad en el manejo de los negocios y el aumento general en la actividad comercial, han hecho que los administradores de las empresas requieran de profesionales independientes en el área de la contaduría pública, con el objeto de ayudarlos a resolver sus problemas en la mejor forma posible. Es por ello, que los servicios que prestan las firmas de contadores públicos han estado evolucionando y continuarán evolucionando de acuerdo a los cambios y exigencias que se dan en el ámbito de los negocios en el mundo. Estos cambios se deben al desarrollo de la economía y la globalización.

Es importante aclarar que el outsourcing no es un servicio especial, sino es una forma de prestar uno o varios servicios, que seria interesante en futuras investigaciones determinar que servicios profesionales se prestan a través de esta modalidad.

Con el propósito de conocer los servicios que prestan las firmas en el municipio Maracaibo y la evolución de los mismos, se les preguntó en la encuesta, que servicios prestaban al inicio de sus operaciones y que servicios prestan actualmente, obteniendo los resultados que se muestran en el Gráfico 2, observando que todas las firmas encuestadas han mantenido

\section{Gráfico 2 \\ Servicios Profesionales que prestan las firmas de contadores públicos del municipio Maracaibo}

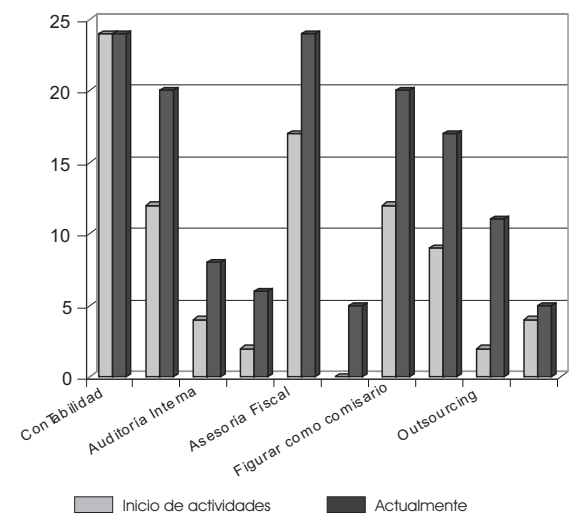

Fuente: Elaboración propia sobre la base de los resultados obtenidos en las encuestas 
desde el inicio de sus operaciones hasta diciembre de 2002 el servicio de contabilidad, mientras que algunas firmas se fueron incorporado progresivamente a los demás servicios de: auditoria externa, auditoria interna, auditoria operacional, asesoría fiscal, auditoria de sistemas de información, figurar como comisario, consultoría gerencia y outsourcing, observando un crecimiento significativo en estos servicios.

Estos resultados confirman, que realmente los servicios que prestan las firmas, han evolucionado, incluso algunos contadores públicos, manifestaron que dada la crisis económica que atraviesa el país y la competencia profesional que existe a nivel local se han visto en la necesidad de diversificar sus servicios, lo cual es similar a lo que está sucediendo a nivel internacional, donde el mercado demanda cada día menos servicios de auditoria y contabilidad y más servicios de asesoría con valor agregado.

\section{Personal de las firmas de contadores públicos}

Por pequeña que sea una firma, es necesario que existan reglas claras con respecto a la administración de personal. La práctica ha demostrado que se deben buscar personas de menor grado de instrucción profesional, que ejecuten trabajos de contabilidad, mensajería, digitación, entre otros, ya que si éstos recaen en un ejecutivo, le limita el tiempo para promover y proyectar la misma, en consecuencia las firmas deben tener un personal administrativo $y$ otro profesional.
Para mantener la competencia de los servicios profesionales que prestan las firmas, es necesario que el reclutamiento de personal incluya ciertos requisitos para su selección, como: promedio académico, conocimientos de sistemas de información, ser bilingüe (Inglés-Español), que tengan habilidades para desarrollarse profesionalmente, para comunicarse y trabajar en equipo.

La profesión de la contaduría pública es dinámica y compleja, debido a la modificación con cierta frecuencia de los aspectos de contabilidad, auditoria, informática, y los aspectos fiscales. El profesional, debe estudiar, actualizarse y aplicar los Principios de Contabilidad Generalmente Aceptados (PCGA), las Normas y Procedimientos de Auditoria (DNA), las Normas Internacionales de Contabilidad (NIC) y las Normas Internacionales de Auditoria (NIA), que se hacen necesarias por la presencia de la globalización y la internacionalización de las empresas y de la economía nacional.

Además de los principios y normas antes mencionados, el contador público, deberá conocer y aplicar las normas particulares que ha emitido la Comisión Nacional de Valores (CNV), la Ley General de Bancos y Otras Instituciones Financieras, La Superintendencia de Bancos, la Superintendencia de Empresas de Seguros y Reaseguros y la Superintendencia de Cajas de Ahorros entre otros organismos de control.

De igual manera, "es de especial interés para el contador público, en el rol de auditor y asesor, el estudio y actualización de conocimientos de las leyes tributarias vigentes con sus continuas modifi- 
caciones y nuevas promulgaciones. Todo esto convierte a la contaduría pública en una profesión difícil y exigente" (Torres, 2002:20-21).

Por lo tanto, durante toda la vida del personal profesional de las firmas, es muy importante que se mantenga una educación continua de alto valor, con el objeto de estar mejorando constantemente los conocimientos y habilidades. Desde luego, el éxito de la capacitación del personal de las firmas de contadores públicos depende en gran parte de la contribución particular del personal.

La firma tiene el compromiso de proveer el más alto servicio profesional a sus clientes. Asimismo reconocer que la calidad profesional del trabajo depende de quienes lo desarrollan, por lo tanto, tiene el compromiso de entrenar técnicamente y desarrollar profesionalmente a su personal a su máxima capacidad. El adiestramiento técnico debe cubrir un número mínimo de horas anuales.

Con el fin de garantizar el desarrollo profesional y la identificación con los costos de los servicios que prestan las firmas, el personal es clasificado en categorías, las cuales se designan básicamente en función a la experiencia y a la habilidad para manejar los trabajos, incluyendo las relaciones con el cliente y con el personal de la misma, siendo las más usuales las de: socio, gerente, supervisor, encargado de trabajo o senior, asistente y personal administrativo (Instituto Mexicano de Contadores Públicos, 1999).

Sobre la base de las entrevistas realizadas a las veinticuatro firmas seleccionadas, se realizó la descripción de las actividades que realiza el personal de cada una de estas categorías:

\subsection{Socio}

Son responsables de la dirección de la firma. El socio de la firma deberá reunir ciertas características tanto técnicas, profesionales, de proyección y personales entre otras, para poder ejercer un liderazgo, que le permita proyectar la firma y la profesión que representa.

Además de las características antes indicadas, el socio por ética deberá tener experiencia profesional, que garantice el cumplimiento de las normas de actuación profesional, ser innovador, constructivo y atento a las necesidades de sus clientes, tener capacidad para tomar decisiones y presentar alternativas de solución, tener facilidades de expresión oral y escrita y poder de convicción, ya que es el representante ante sus clientes.

\subsection{Gerente}

La función del Gerente es la continuación del servicio de un socio, por lo tanto, un gerente, debe actuar como socio y tener mentalidad como tal. Por otra parte, en adición a los requisitos técnicos, deberes y responsabilidades de un supervisor, debe tener la capacidad para reconocer y llevar a cabo aquellos factores que ayudan al desarrollo de la firma. Técnicamente deberá ser experto en el área que desarrolla y tener conocimientos sólidos en otras áreas. Dentro de sus actividades principales están las de: preparar y presentar las propuestas de servicios, sugerir planes de trabajo, mantener contacto con los clientes mediante visitas, selección de personal requerido, entre otras. 


\subsection{Supervisor}

Es aquel que propone la planificación de los trabajos asignados y coordina el trabajo de campo con el personal a su cargo, realiza frecuentemente visitas a clientes y mantiene estricto contacto con los mismos; ya que él también interviene en la preparación y participación de las propuestas; reorientación del enfoque de una auditoria o de algún trabajo especial según sea necesario; revisar los informes a emitir por parte de la firma hacia el Cliente.

Mantiene relaciones adecuadas con los clientes, con los gerentes y los socios de la firma, por lo general tienen una experiencia de cuatro o cinco años como mínimo, posee conocimientos técnicos sólidos en el área asignada, conoce ampliamente aspectos fundamentales de otras áreas, tiene habilidades para resolver problemas, en algunas firmas participa activamente como instructor en los cursos impartidos.

Dentro de sus responsabilidades está la planeación oportuna de los trabajos, con calidad y en el menor tiempo posible, terminar totalmente los trabajos de acuerdo al alcance planeado, supervisar varios trabajos visitando físicamente las empresas, orientar técnicamente al encargado o senior, así como a los asistentes, en cuestiones técnicas, motivando al estudio y superación profesional, está alerta a localizar problemas técnicos así como su pronta solución.

\subsection{Encargado de trabajo o Senior}

Está encargado de la ejecución de los trabajos, siguiendo las indicaciones del Supervisor o Gerente, coordina e ins- truye en el trabajo de campo a los asistentes a su cargo. Realiza esta función simultáneamente en varios clientes, trabaja estrechamente con los representantes del cliente.

La responsabilidad inicial ante los clientes recae en la buena función de un encargado, difícilmente lo que omite un encargado será detectado por el Socio, por eso se consideran como la columna vertebral en la estructura de la firma, sobre él recae la responsabilidad total del desarrollo de los servicios profesionales en el campo de trabajo, por lo que debe asegurarse, que el trabajo se desarrolle de conformidad con los programas y con base a las instrucciones recibidas, de acuerdo al alcance establecido.

También son responsables del entrenamiento en el campo de trabajo del personal bajo su supervisión, por lo que deben comunicarse constantemente con sus asistentes para cerciorarse que entendieron la naturaleza del alcance del trabajo, debe revisar todos los papeles de trabajo, determinar los puntos pendientes $y$ asegurarse de que sean cubiertos oportunamente y realizar el trabajo en las áreas más difíciles o de riesgo.

Por lo general, son personas con experiencia de dos o tres años en el área, debe tener amplios y profundos conocimientos técnicos, hábitos de estudio y de la investigación en la literatura técnica, conocimientos en los sistemas de información. Al detectar algún problema, debe comunicarse oportunamente con el supervisor, gerente o socio, y presentar varias alternativas para la solución, siempre que estén fundadas en argumentos técnicos.

Son los responsables de preparar los informes como resultado del trabajo 
realizado, llevar un control estricto del presupuesto de tiempo, hacer seguimiento para que los informes se entreguen a tiempo, sobre la marcha.

\subsection{Asistentes}

Dentro de los asistentes hay varias categorías de acuerdo a la experiencia y conocimiento técnico, aquí se incluyen los aprendices, quiénes ejecutan pruebas sencillas. Para ser asistente se debe tener conocimientos sólidos en el área que esté trabajando, sin olvidar aspectos básicos de las otras funciones; ejecutar secciones completas de un trabajo, manejar el presupuesto de la sección que le ha sido asignada, mantener comunicación oportuna con el encargado de trabajo y supervisor, para informar cualquier dificultad o duda presentada en la ejecución del trabajo.

Por otra parte, de acuerdo al grado de experiencia, deberá supervisar y orientar a los asistentes que le hayan sido asignados, asegurarse que el trabajo suyo y de sus ayudantes ha sido debidamente concluido.

\subsection{Personal Administrativo}

Incluye al personal que ejecuta trabajos de administración interna, mensajería, recepcionistas, secretarias, entre otros.

En la Tabla 3, se muestra la distribución del personal de las firmas encuestadas en cada una de las categorías descritas anteriormente.

Como se puede observar, el mayor porcentaje de personal se encuentra en las categorías de socio, asistentes y personal administrativo; teniendo el mayor promedio de antigüedad de años las categorías de socio y gerente, sobre quienes recae la responsabilidad directa de los servicios que presta la firma.

Por otra parte, se tiene que el $58 \%$ de las firmas encuestadas tienen menos de 10 personas laborando, 38\% tienen entre 20 y 30 personas y un $4 \%$ más de 30 personas, al compararlo con el número de clientes que tiene cada una de ellas para el año 2002 , se observa que el $17 \%$ tiene menos de 10 clientes, el $38 \%$ entre 20 y 30 clientes y el $46 \%$ tiene más de 30 clientes, tales resultados indican que no existe relación entre el número de perso-

\section{Tabla 3}

\section{Clasificación del Personal}

\begin{tabular}{lccc}
\hline Categorías & Cantidad & $\%$ & $\begin{array}{c}\text { Antigüedad } \\
\text { (Años Promedio) }\end{array}$ \\
\hline Socio & 52 & 19 & 10 \\
Gerente & 19 & 7 & 7 \\
Supervisor & 30 & 11 & 5 \\
Encargado de trabajo o Senior & 39 & 14 & 3 \\
Asistente & 87 & 31 & 3 \\
Personal Administrativo & 50 & 18 & 4 \\
Total & $\mathbf{2 7 7}$ & $\mathbf{1 0 0}$ & \\
\hline
\end{tabular}

Fuente: Elaboración propia sobre la base de los resultados obtenidos en las encuestas. 
nal que tienen las firmas y el número de clientes a los que prestan su servicio, lo cual se debe a que no existe uniformidad en el tamaño y características de sus clientes.

También, es importante resaltar que todas estas categorías no aplican a todas las firmas, esto depende del tamaño de la misma, a medida que sea más pequeña, las categorías de mayor nivel van absorbiendo las funciones que deben ejercer las categorías de mas bajo nivel, por lo que en muchas firmas el socio cumplirá con las funciones asignadas para cada una de las categoría anteriormente descritas.

Basados en las entrevistas efectuadas, se observó que algunos socios, habían iniciado su proceso de desarrollo profesional en las firmas transnacionales, por tal razón, es que el origen de estas categorías se debe a las estructuras de dichas firmas, que tienen como política contratar estudiantes del último año de la carrera o recién graduados, con el fin de adiestrarlos y mantenerlos actualizados de acuerdo al grado de responsabilidad que tengan en relación con las asignaciones de trabajo y dar la posibilidad de llegar a ser socio de la firma.

\section{Formación académica}

La formación académica es indispensable en una firma para lograr la óptima calidad de los servicios que se prestan, esta formación se puede lograr a través del estudio y el entrenamiento técnico y práctico en el campo de trabajo. Para lograr los mejores resultados se debe elaborar un plan de entrenamiento de acuerdo a las necesidades de la firma y el tipo de personal que se tenga, tomando en consideración los siguientes aspectos: los servicios que presta la firma con más frecuencia, especialidad del personal, experiencia del personal, el plan general de trabajo y de cursos para el personal.

La continuación de la educación es el requisito mas importante para lograr mantener la competencia profesional y es responsabilidad de los socios de la firma garantizar que los miembros de la misma, mantengan su desarrollo profesional, para lo cual es necesario proporcionar un entrenamiento formal mediante cursos de actualización y un entrenamiento específico a través de las experiencias en el trabajo, el cual debe ser supervisado.

A nivel nacional, el organismo gremial autorizado para desarrollar la profesión de la contaduría pública en Venezuela, es la Federación de Colegios de Contadores Públicos de Venezuela, quién agrupa a los agremiados de la contaduría pública, encargada de emitir las disposiciones reglamentarias inherentes al ejercicio profesional, normas de aceptación general en la profesión, pronunciamientos inherentes a la ética del contador público y el régimen disciplinario. A nivel local, el organismo gremial autorizado es el Colegio de Contadores Públicos del Estado Zulia, dentro de sus propósitos está promover el mejoramiento profesional de sus miembros en el estado Zulia.

Dada la competencia que existe actualmente en dar un mejor servicio, las firmas se ven en la necesidad de mantener un personal profesional competente, que constantemente estén actualizando los conocimientos, actitudes y habilidades del ejercicio profesional. La calidad del personal debe incluir la ética, inteligencia, dedicación y responsabilidad. 
Para mantener el nivel de competencia, la mayoría de las firmas ubicadas en el municipio Maracaibo, asisten a los cursos de actualización profesional dictados por el Instituto de Desarrollo Profesional del Colegio de Contadores Públicos del Estado Zulia (IDEPRO), cuyo objetivo es contribuir con la formación y actualización del recurso humano en las áreas de administración y gerencia. Dicho instituto, mantiene programación constante de actividades, principalmente talleres y cursos de actualización y desarrollo profesional, conferencias, jornadas gerenciales, financieras, laborales y tributarias, impartidas por profesionales de alto nivel.

De acuerdo con Catacora (2002), uno de los dilemas a los cuales se enfrenta la profesión contable y su ejercicio profesional, es el referente a la formación continua que debe recibir el contador público en ejercicio, con la finalidad de garantizar un adecuado desempeño y práctica en un ambiente competitivo y con altos estándares de calidad. La importancia de la información financiera para la toma de decisiones, exige que la formación de los profesionales responsables de elaborarla, cambie el enfoque tradicional de cursos de acreditación en un aula física e incluyan el traslado del profesional a un lugar en el cual se impartan los conocimientos, por un enfoque moderno, donde exista más un contacto lógico entre las entidades responsables de impartir la educación de los profesionales de la contaduría y aquellos que guían su formación.

Plantear un modelo normativo que acerque estas realidades, requiere una visión global que haga abstracción de la ubicación física del contador del siglo $\mathrm{XXI}$, para luego asegurar los medios que le permitan acceder a esa constante actualización con una formación y un mínimo nivel de calidad.

Mediante la encuesta, se pudo obtener la información del nivel de formación académica del personal de las firmas, cuyos resultados se muestran en el Gráfico 3, observándose que el $60 \%$ son profesionales, incluyendo licenciados en contaduría pública $(55 \%)$, abogados (4\%) e ingenieros (1\%); un $22 \%$ corresponde a estudiantes de Contaduría; un $10 \%$ a otros que corresponde al personal administrativo y un $8 \%$ a los técnicos superiores en contaduría.

\section{Evaluación y promoción del personal}

El programa de evaluación y promoción es necesario para cualquier tipo de organización, ya que éste permite mejorar el conocimiento y capacidad profesional, logrando identificar el personal que tiene mayor potencial y sirve a la vez de instrumento para los planes de sucesión de socios en las firmas. Este programa también permite la asignación de sueldos para el personal.

El factor más importante dentro de una firma es el recurso humano, de allí la importancia de contar con un programa de promoción, que estimule la competitividad, permitiendo así mantener un personal capacitado.

En el procedimiento de promociones se deben preparar lineamientos que describan las responsabilidades en cada nivel y el desempeño esperado para la decisión en cuanto a las promociones. Los criterios deben estar debidamente definidos entre los cuales se destacan: conoci- 
mientos técnicos, capacidad de análisis y juicio, habilidades de comunicación, liderazgo, su comportamiento con el cliente, actitud profesional. Los criterios de evaluación deben estar sistematizados e informados al personal (Federación de Colegio de Contadores Públicos, 2001).

De acuerdo con lo indicado en el Grafico 4 , el $67 \%$ de las firmas evalúan su personal en forma anual, un $25 \%$ en forma semestral y un $8 \%$ corresponde a las pequeñas firmas, que la mayoría de las actividades son realizadas por sus socios.

Como se puede observar en el Gráfico 5 , el $45 \%$ de las firmas realiza promoción de su personal en forma anual, el $17 \%$ lo realiza cada 2 años y un $38 \%$ de acuerdo al crecimiento natural de la organización.

\section{Modelo organizativo de las firma de contadores públicos}

"La estructura organizacional se refiere a la forma en que las actividades de una organización se dividen, organizan y coordinan" (Stoner y Freeman, 1994:336).

Según este autor, los departamentos de una organización pueden estructurarse formalmente de tres maneras: por función, por producto o mercado y en forma matricial.

\section{Gráfico 3 Nivel de educación del personal de las firmas}

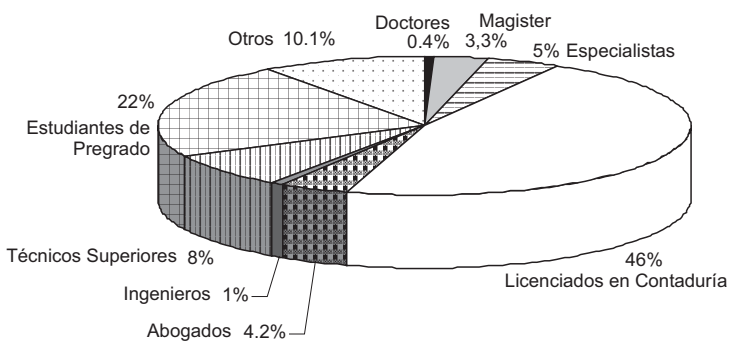

Fuente: Elaboración propia sobre la base de los resultados obtenidos en las encuestas.

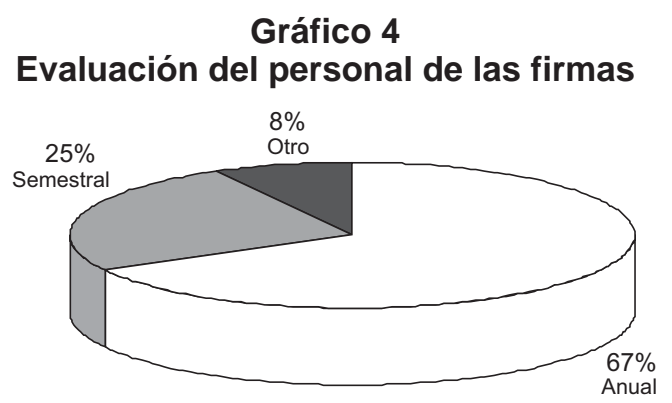

Fuente: Elaboración propia con sobre la base de los resultados obtenidos en las encuestas. 


\section{Gráfico 5 \\ Promoción del personal de las firmas}

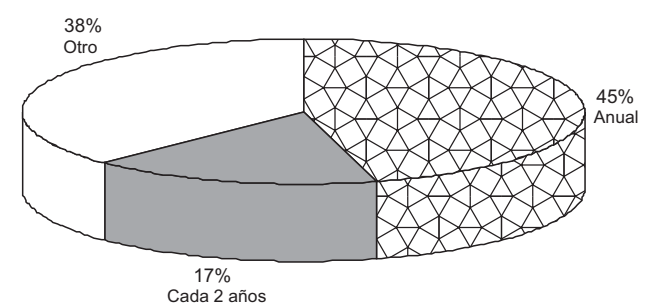

Fuente: Elaboración propia sobre la base de los resultados obtenidos en las encuestas.

\section{Gráfico 6 Estructura organizativa de las firmas}

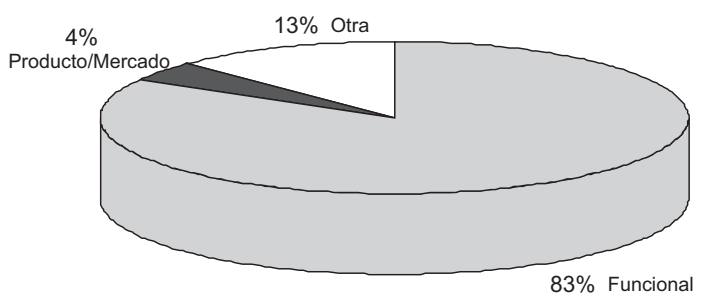

Fuente: Elaboración propia sobre la base de los resultados obtenidos en las encuestas.

La organización por función reúne en un departamento a todos los que realizan una actividad o varias actividades relacionadas entre sí.

La organización por producto o mercado, frecuentemente denominada organización por división, reúne en una unidad de trabajo a todos los que intervienen en la generación y mercadotecnia de un producto o grupos afines de productos, a los que se hallan en cierta región geográfica o a los que tratan con determinado tipo de cliente.

En la organización matricial, existen simultáneamente dos tipos de estructura, por función y por división. Los departamentos funcionales poseen autoridad para las actividades y estándares profesionales de sus unidades; pero se crean equipos de proyectos, según se necesite, para poder desarrollar actividades específicas. De varios departamentos funcionales se seleccionan los integrantes del equipo que están subordinados a un administrador de proyectos, responsable por los resultados del trabajo en equipo.

Como se puede observar en el Gráfico 6 , el modelo organizativo que prevalece es el funcional, donde la estructura organizativa está bajo la dirección y administración de la asamblea de socios. De acuerdo al tamaño y servicios que presta la firma, se establecen divisiones o departamentos por áreas de servicio, los más comunes son: contabilidad, auditoria, tributaria, sistemas de información y asesoría en general, como toda organización tiene su asesor legal. 


\section{Conclusiones}

Tomando en consideración que este trabajo de investigación se limitó a las firmas nacionales del municipio Maracaibo, ya que se excluyeron aquellas que representan firmas transnacionales, por las limitaciones de obtener de ellas información, es necesario que la Dirección de la Escuela de Administración y Contaduría y los centros de investigación de la Facultad de Ciencias Económicas y Sociales, establezcan un programa de acercamiento con aquellas firmas representantes de transnacionales, con el objeto de sensibilizarlas y establecer acuerdos que permitan obtener insumos para la formación del contador público y la investigación en el área de la Contaduría, que permitan determinar las competencias que capacitan a los contadores públicos para ser exitosos, el rol que deben cumplir los educadores, las organizaciones profesionales y las empresas en general; teniendo presente que estas organizaciones se caracterizan por hacer inversiones en el área de investigación.

En cuanto a los resultados obtenidos, se observa que en los últimos cuatro años no se han creado nuevas firmas, producto de la crisis política y económica que ha experimentado Venezuela en este período, adicionalmente se pudo observar que se han dado traslados de clientes de unas firmas a otras, como consecuencia de la competitividad que existe en los servicios que prestan las firmas.

Por otra parte, al vincular el crecimiento de las firmas con la cantidad de profesionales de la contaduría pública egresados de la Universidad del Zulia, se pudo evidenciar que el incremento de los egresados ha sido en mayor proporción que el crecimiento de las firmas.

El incremento en el número los egresados de contaduría pública de la Universidad del Zulia, es contrario a lo que está sucediendo en los Estados Unidos y Puerto Rico, siendo un punto de reflexión e investigación, que permita evaluar el proceso de educación profesional que actualmente se aplica en la Escuela de Administración y Contaduría, para verificar si el mismo está en función de lo que requiere el mercado.

Todas las firmas han prestado desde su inicio de actividades el servicio de contabilidad y a través del tiempo se han ido incorporando los servicios de asesoría fiscal, auditoria externa, figurar como comisario y consultoría gerencial, entre otros.

El mayor porcentaje de personal se encuentra en las categorías de socio, asistentes y personal administrativo, teniendo mayor antigüedad de años dentro de la firma las categorías de socio y gerente. Para prestar los servicios profesionales, el personal profesional de la firma debe ser competitivo, debe conservar un estricto apego a las leyes y a la ética, para mantener su credibilidad ante sus clientes y la sociedad, es necesario mantener una educación continua de alto valor, con el objeto de estar mejorando constantemente los conocimientos y habilidades.

De acuerdo con el número de personal que tienen las firmas, se pueden catalogar como pequeñas y medianas organizaciones, dentro de las cuales no existe uniformidad en el tamaño y características de sus clientes.

Algunas firmas dependiendo del tamaño de la misma, presentan categorías 
diferentes, ya que se pudo evidenciar que en las firmas pequeñas las categorías de mayor nivel (socio) absorben las funciones que ejercen las categorías de más bajo nivel (gerente, supervisor, encargado de trabajo o senior y asistentes).

Un $55 \%$ del personal corresponde a licenciados en contaduría pública (15\% tienen maestría o especialidad), un $22 \%$ a estudiantes de Contaduría, un $10 \%$ a personal administrativo y un $8 \%$ a los técnicos superiores en contaduría. Para mantener el nivel de competencia profesional, la mayoría de las firmas, asisten a los cursos de actualización profesional dictados por el Instituto de Desarrollo Profesional del Colegio de Contadores Públicos del Estado Zulia (IDEPRO).

En cuanto a la evaluación y promoción del personal no existe uniformidad, observando que el $67 \%$ realiza la evaluación en forma anual, un $25 \%$ en forma semestral y un $8 \%$ no realiza evaluación. En cuanto a la promoción, el $45 \%$ la efectúa en forma anual, el $17 \%$ cada dos años y $38 \%$ de acuerdo al crecimiento natural de la firma.

Dentro de las firmas prevalece el modelo organizativo funcional, adaptando su estructura de acuerdo a su tamaño y a los servicios que prestan.

La diversificación de los servicios prestados por las firmas y el conocimiento público de los fraudes financieros en grandes empresas internacionales auditadas por reconocidas firmas, ha provocado el surgimiento de nuevas normativas que regulan la actuación del contador público a nivel mundial, con la finalidad de reforzar sus principios éticos, haciendo hincapié en la revelación de información suficiente sobre los estados financieros y la independencia que debe mantener en la ejecución de su trabajo. Sin embargo, existe poca difusión de estas disposiciones por parte del gremio a nivel nacional, ya que la Federación y los Colegios de Contadores Públicos están abocados actualmente al proceso de adopción de las Normas Internacionales de Contabilidad (NIC), dejando de lado todo lo referente a reforzar los valores éticos y la calidad del ejercicio profesional.

Todas estas consideraciones indican que la contaduría se encuentra en proceso de transformación muy importante, donde las empresas cada día requieren más asesores gerenciales. Por lo tanto, se debe investigar el origen de estos cambios, para poder determinar hacia donde va la profesión y en función de esto, revisar los programas de formación académica, de tal forma que los mismos se adapten a las nuevas realidades. Una actuación profesional basada en valores será más coherente y estable que una basada sólo en el conocimiento del deber ser.

\section{Referencias Bibliográficas}

Asociación de Auditoria y Control en Sistemas de Información. (2002). Disponible en http://www.isaca.cl/standares. html. 07/05/2003

Catacora, Fernando (2002) Avances tecnológicos en la era del conocimiento. Del Contador de papel al Contador digital. Trabajo de investigación presentado en el Congreso Nacional de Contadores Públicos. Panamá.

Conferencia Interamericana de Contabilidad (1997), Disponible en http://www.cortedecuentas.gob.sv. 08/05/2003

Congreso Nacional de la República de Venezuela (1973), Ley de Ejercicio de la 
Contaduría Pública. Gaceta Oficial No. 30.216. Ordinaria

Federación de Colegio de Contadores Públicos de Venezuela (1996), Código de Ética Profesional del Contador Público Venezolano. Caracas, Venezuela

Federación de Colegio de Contadores Públicos de Venezuela (2001), Control de Calidad en el ejercicio profesional. Declaración de Normas de Auditoria (DNA) № 12. Caracas, Venezuela.

García, Rafael (2002) Outsorcing. AVANTEL. Disponible en: http://www.avantel. net/ rjaguado/outsour.html. 07/05/2003

Huertas, Yvonne (2002), Perfeccionamiento Profesional del Contador: Una ventaja competitiva. Trabajo de investigación presentado en el Congreso Nacional de Contadores Públicos. Panamá.

Instituto Mexicano de Contadores Públicos, A.C. (1999), Manual para Estructurar y Organizar Pequeñas y Medianas Firmas de Contadores Públicos. Editores e Impresores FOC, S.A. México.

Instituto Mexicano de Contadores Públicos (2004), Boletín 3020 Control de Calidad en las Firmas de Contadores Públicos. México.
León, Mauricio (2003), Auditoria Interna, un enfoque sistémico y de mejora continua. Disponible en Monografías de Auditoria en www.redcontable.com 08/12/2003

Morrow, J.F. (2000), Una transformación para la formación de Contadores Públicos. Instituto Americano de Contadores Públicos. New Cork, EEUU.

Navarro, Yasmile (2003), La Masificación Estudiantil en la Escuela de Administración y Contaduría Pública. Trabajo de Ascenso para optar a la categoría de Asociado. Universidad del Zulia. Maracaibo, Venezuela.

Rosales, Lennin (1999), Contaduría Pública. Aspectos de actualidad en una de las profesiones de mayor auge $y$ crecimiento en Venezuela. Fondo editorial del Contador Público Venezolano. Caracas, Venezuela.

Stoner, James y Freeman, Edward (1994), Administración. $5^{\circ}$ Edición. Prentice Hall. México.

Torres, Noris (2002), Estrategias Financieras para maximizar los beneficios en las Pequeñas y Medianas Firmas de Contadores Públicos del Municipio Maracaibo. Trabajo de grado para optar al título de Magíster en Gerencia de Empresas Mención Gerencia Financiera. Universidad del Zulia. Maracaibo, Venezuela. 